\title{
CASTLEMAN'S DISEASE MIMICKING CAROTID BODY TUMOR
}

\author{
Hanzel P. ${ }^{1}$, Calkovsky V. ${ }^{1}$, Sinak I. $^{2}$, Szepe P. ${ }^{3}$, Zelenak K. ${ }^{4}$, Hajtman A. ${ }^{1}$ \\ ${ }^{1}$ Clinic of Otorhinolaryngology and Head and Neck Surgery, ${ }^{2}$ Clinic of Transplant, Visceral and Vascular Surgery, \\ ${ }^{3}$ Department of Pathological Anatomy, ${ }^{4}$ Clinic of Radiodiagnostics, Comenius University, Jessenius Faculty of \\ Medicine and University Hospital Martin, Martin, Slovakia
}

\begin{abstract}
The authors present a case of 41-year-old patient with unicentric type of Castleman's disease in the neck imitating carotid glomus tumor. This rare condition can affect any lymph-node in the body and neck localization occurs only in $14 \%$ of cases. The case when Castleman's disease simulating chemodectoma have not been described yet in the literature. The authors give details on the course of the disease, its diagnosis and treatment and the discussion focuses on the reasons why the auxiliary imaging methods have led to the clinical diagnosis of carotid glomus tumor, and why the treatment was chosen.
\end{abstract}

Keywords: Castleman's disease, carotid body tumor, chemodectoma, Castleman's disease therapy, preoperative embolization

\section{INTRODUCTION}

Castleman's disease is a rare, usually benign disease of unclear etiology which is now considered an immunopathological process. Castleman with his colleagues first published it in 1956. It was described as benign hyperplasia of mediastinal lymph-nodes, similar to thymus tissue [1]. Some authors use synonymous terminology of this disease: angio-folicullar hyperplasia, angio-fibroid hamartoma, follicular lymphoreticuloma, giant cell hyperplasia, benign giant lymphoma. It could, however, lead to misinterpretation of a neoplasia or hamartoma and therefore the most commonly used name is Castleman s disease.

In 1972 Keller with co-workers have described two different histological types of the disease: hyaline-vascular (91\% of cases) and plasma-cell (9\% of cases) [2]. The disease can occur as an unicentric type localized in one anatomic area or a multicentric type - a systemic disorder with disseminated lymphadenopathy. The disease is unicentric in most cases of hyaline-vascular type; plasma-cell type is represented only in about $10 \%$ of cases. The multicentric variation is seen almost always in plasma-cell type [3] and clinical development of the disease often leads to malignancy, both in terms of development of malignant lymphoma, or sarcoma of dendritic reticular cells.

Although Castleman's disease could be theoretically found in any lymph-node in the body, the chest is the most common location (60\%). The neck has been reported in only about $14 \%$ of cases [4]. At head and neck, Castleman's disease is preferentially located in perijugular lymph-nodes in the submandibular and parotid region [5].

On the basis of clinical status, physical examination and auxiliary imaging techniques Castleman's disease was often diagnosed as a different nosological unit (MTS cancer to lymph-nodes, lymphoma, schwannoma, a pathological process in the thyroid, hepatocellular carcinoma, tumor of adrenal glands and others) until the histopathological examination led to correct diagnosis. The cases in which Castleman's disease imitates chemodectoma, are not reported in the literature and this is the first study doing so.

Address for correspondence:

Pavel Hanzel, MD, Clinic of Otorhinolaryngology and Head and Neck Surgery, Jessenius Faculty of Medicine, Comenius University and University Hospital Martin, Kollarova Str.2,

03601 Martin, Slovakia

Phone: +421-43-2633714; e-mail: pavelhanzel@gmail.com 


\section{CASE REPORT}

A 41-year-old patient with massive resistance on the left side of the neck is presented. Tumor was located in the middle third of the neck on the left and first diagnosed at the age of two years. In childhood the patient was operated 4 times (1974, 1976, 1981 and 1986). Histopathological findings were repeatedly ambiguous. The conclusion of the last examination in 1986 was: nonspecific lymphadenopathy. The course of the last operation (1986) as recorded in the documentation was complicated by massive bleeding requiring surgical suture of damaged wall of a.carotis interna (ACI) 1.sin. and the patient required blood transfusion.

In the further course of the disease the tumor was slowly expanding. In spite of that, the proposed surgical treatment was rejected by patient s parents and after attaining full age also by the patient herself. She was sporadically followed up by otorhinolaryngologist. The size of the tumor was virtually unchanged since puberty. The last time, the excision for histopathological examination was recommended 2 years ago but it was refused by the patient. The possible zoonotic disease was excluded by infectologist.

At the age of 41 years, 3 months before admission to the Clinic of Otorhinolaryngology and Head and Neck Surgery, Jessenius Faculty of Medicine, Comenius University (JFM CU), Martin and University Hospital Martin (UHM), the patient observed a tumor growth, mainly in cranial part that was associated with a dull pain of fluctuating intensity.

At the ENT examination, in addition to increased volume of lesions, newly formed left vocal cord paralysis was detected. At ultrasound examination, a well-bounded packet of vascularized lymph-nodes $7 \times 4 \mathrm{~cm}$ surrounding a.carotis communis (ACC) and its bifurcation was found without obturating or infiltrating blood vessels. V.jugularis interna (VJI) was pushed dorsolaterally.

CT scan revealed a huge vascular tumor of rough but relatively sharp edges on the left side of the neck size $5.5 \times 6.5 \times 12.5 \mathrm{~cm}$. It ranged from jugular to the infratemporal fossa almost to the carotic canal. ACC, a.carotis externa (ACE) and ACI on the left side were inside in the expanded tumor. Due to pressure of the tumorous masses ACI has been thinning. VJI on the left was obturated and replaced by a widespread network of veins ventrally to the tumor. The tumor was located in 3 to $3.5 \mathrm{~cm}$ large node with central necrosis, that was not detected in the last CT scan two years ago (Figs. 1, 2, 3).

Due to the suspicion of a malignant transformation of the tumor, the patient was admitted to the Clinic of Otorhinolaryngology and Head and Neck Surgery JFM CU and UHM for further diagnosis and treatment.

Because of the tight relationship of tumor to major vessels angiography was indicated. It revealed hypervascularized tumor in the left part of the neck supplied by branches of ACE 1.sin. and involving bifurcation of ACC 1.sin.

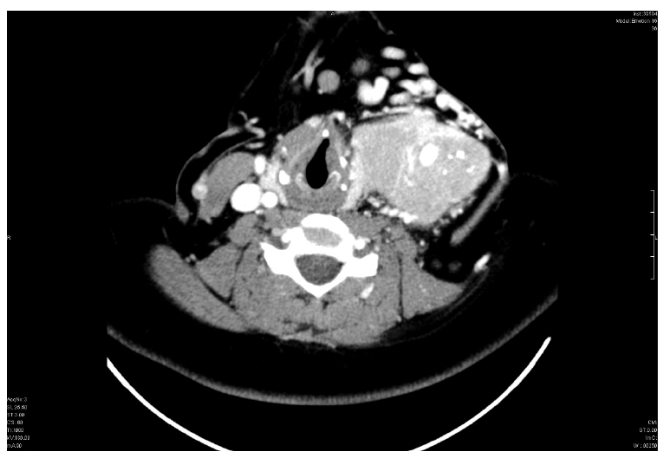

Fig 1 CT scan axial cut

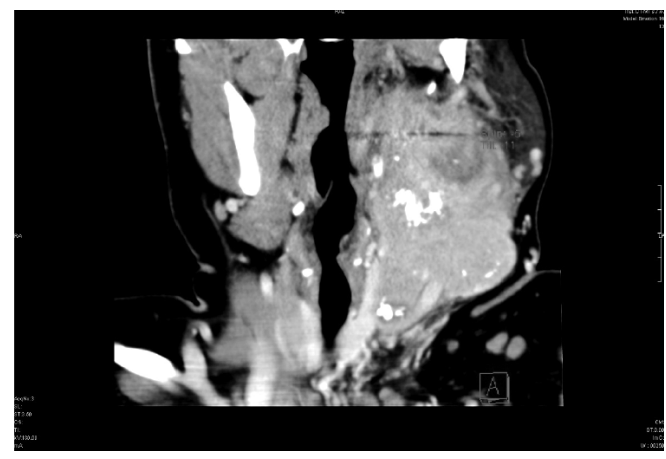

Fig 2 CT scan frontal cut 


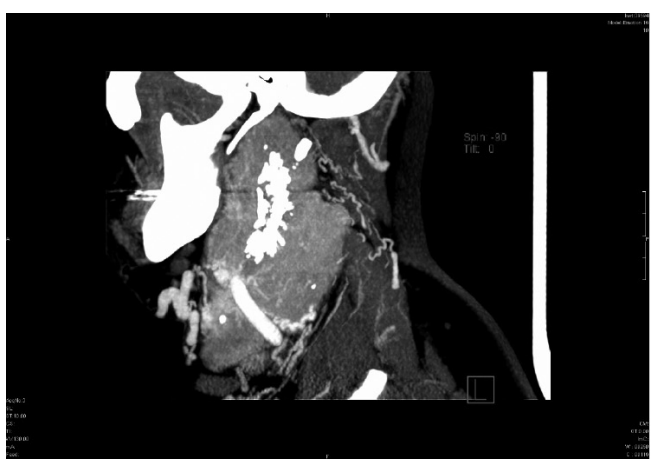

Fig 3 CT scan sagital cut

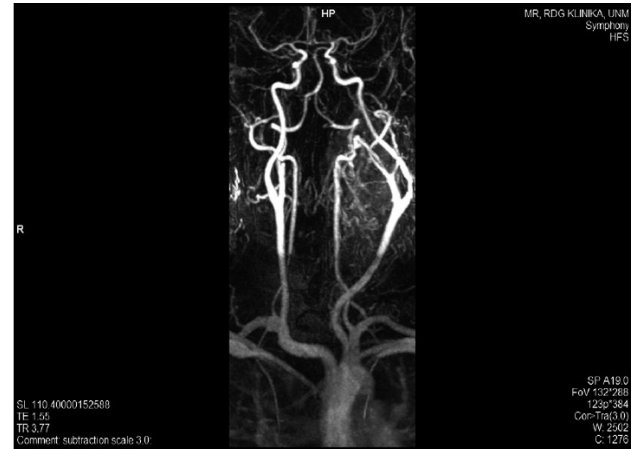

Fig 4 CE-MRA frontal cut

Subsequently, Matas test of ACI 1.sin. was performed. After administration of contrast medium into ACI 1.dx. both a.cerebri anterior (ACA) and a.cerebri media (ACM) were filled bilaterally without delay in venous phases of vessel basin of ACA and ACM on left. After administration of contrast medium into a.vertebralis (AV) 1.sin. vertebrobasillar venous system was filled and through the a.communicans posterior on the left also ACM 1.sin. with no delay in venous phase. After $15 \mathrm{~min}$ of the occlusion test the patient was clinically without motor and phatic disorders. At the end of the test (total length $45 \mathrm{~min}$ ) she described a visual sensation in the left eye („like a flash“), and headache that disappeared with restoration of the blood flow in ACI 1.sin.

Prior to the planned surgical treatment examination of extracranial cerebral arteries by Contrast Enhanced Magnetic Resonance Angiography (CE-MRA) was completed. ACC, ACI and ACE on the right side were without significant hemodynamic changes. Left ACC was involved into the tumor in the length of $3.5 \mathrm{~cm}$ to the bifurcation and it was deviated laterally by about $3 \mathrm{~cm}$. Left ACI was involved into the tumor in $5 \mathrm{~cm}$ and ACE $1 . \sin$. in $2 \mathrm{~cm}$ of their length. Hemodynamically the vessels were without significant changes with homogeneous contrast filling (Fig. 4).

Preliminary diagnosis based on clinical course and auxiliary imaging studies was given as tumor originating from the left carotid artery body. According to the Shamblin's classification it was type III [6] - a large tumor, pressing carotid artery and cranial nerves (in our case n.vagus) whose removal is difficult and often requires reconstruction of the ACI. Vascular surgeon considered the tumor as operable with high risk of serious complications and massive bleeding.

Prior to the planned surgical treatment embolization of the tumor was performed by application of the embolization substances into the branches of a.occipitalis 1.sin. and a.pharyngea ascendens 1.sin. The control application of contrast fluid into ACE and ACC revealed only small contrast areas in the ventrocaudal parts of the tumor on the left probably supplied from branches a.thyroidea sup.l.sin.

At the next day, the patient was operated in co-operation with vascular surgeons. A radical excision of the tumor sized $15 \times 8 \times 7 \mathrm{~cm}$ was performed with ACC, ACI and ACE passing through its center. VJI was fibrotized, n.vagus involved into the tumor, truncus symphaticus was unidentified, n.hypoglossus was intact and separated from the tumor, but in the place of its crossing with ACI the integrity of the vessel was broken. ACC and ACI on the left were therefore replaced by a graft of autologous inerposit of $v$. sap. magna 1.sin. ACE on the left was ligated (Fig. 5, 6). Perioperative blood loss was $1500 \mathrm{ml}$.

A sample of the tumor tissue was examined by perioperative histopathology with conclusion of lymphoid tissue with interfollicular proliferation of uncertain biological significance. Definitive diagnosis was based on immunohistochemical processing: nonmalignant, immunopathological lymph-node proliferation from spectrum of Castleman's disease, hyaline-vascular type „stroma rich“ variant [7] (Fig. 7). 


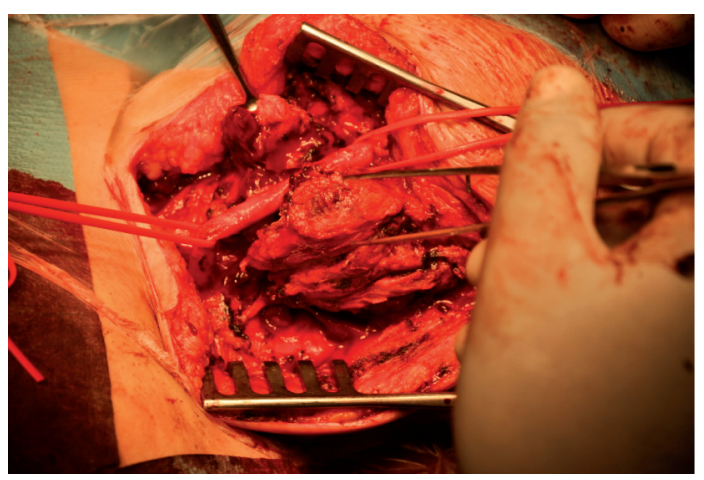

Fig 5 ACC partially removed from tumor

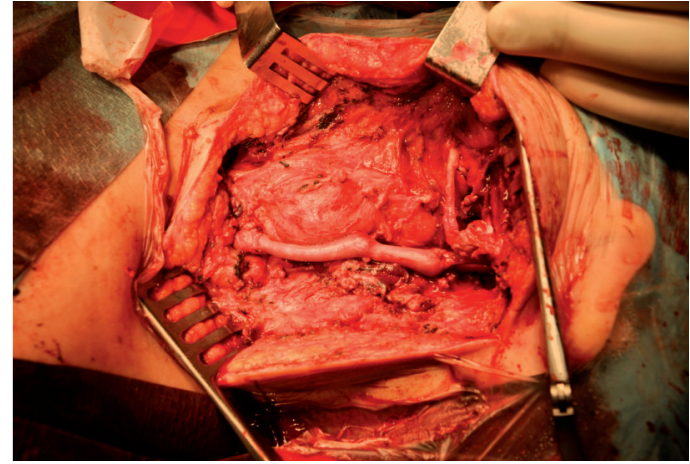

Fig 6 Tumor removed and ACC and ACI replaced by a graft of autologous inerposit

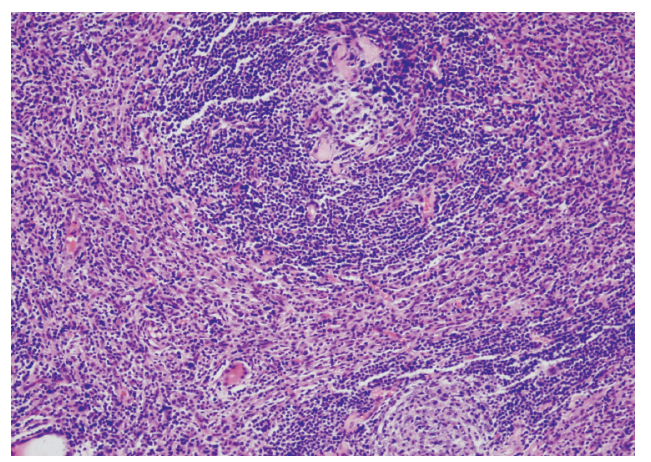

Fig. 7 Hematoxylin and eosin, $10 \mathrm{x}$ magnification

\section{DISCUSSION}

When reviewing the literature on Castleman's disease it was found out that a histopathological diagnosis is more often surprising than expected result, especially in cases with extrathoracic tumor localization. After a more detailed analysis it seems that the disease most often mimicks other processes characterized by the growth of tumor mass. After entering the key words Castleman and mimicking into the database MEDLINE®/PubMed® displayed 14 results, words Castleman/simulating and Castleman/masquerading 2 publications each and words Castleman/imitating 1 publication. The papers identically describe the cases of patients with a clinical diagnosis different from that done after histopathological examination as Castleman's disease. According to these publications the disease mimicks tumors of pancreas, liver, lungs, retroperitoneum, ovary, nerve sheaths, or lymph-nodes, but also sequester in mediastinal space, or malabsorption syndrome [8-15]. In none of the articles studied, Castleman s disease imitated chemodectoma as in our reported patient.

The most common tumors at the point of carotid bifurcation are carotid glomus tumors, but they can be imitated by other expansive processes in this area. For instance, schwannomas of the cervical sympathetic fibers were preoperatively falsely considered as carotid body tumors [16, 17].

Carotid glomus tumors are causing an expansion of carotid artery bifurcation. The increased distance (called "splaying") between ACI and ACE demonstrated by supportive imaging techniques resembles lyre-like picture. Lyre sign is considered a crucial mark in the diagnosis of carotid body tumors [16] and it was present also in our patient (Fig. 4). Chemodectomas are usually easily diagnosed by conventional angiography [17]. In this case report angiography revealed hypervascularized tumor involving bifurcation of ACC 1.sin that has been supplied by branches of ACE 1.sin. Clinical diagnosis was based on these signs. 
Among non-invasive methods ultrasonography can be used. However, in $13 \%$ of cases this technique leads to an incorrect diagnosis of carotid body tumor [18]. The examination was performed also in our patient and 7x4 cm large bounded packet of vascularized lymphnodes involving ACC and its bifurcation was seen.

CT and MR images are useful to determine the extent of tumors as well as their position in relation to the surrounding blood vessels [17]. Both tests supported an expected diagnosis also in our case report illustrating a huge vascularized tumor involving ACC, ACI and ACE.

All above-mentioned imaging techniques are helpful in the diagnosis of extensive vascularized tumors of the neck, but not in all cases they lead to correct clinical diagnosis.

There is no consensus on optimal treatment of Castleman's disease in the literature [19]. Surgical removal is considered the most appropriate therapy for unicentric type of the disease [2, 20-22]. Unresectable unicentric variants of these tumors have been treated by various strategies: primary radiotherapy or incomplete resection [23], and chemotherapy [24]. In some cases, significant reduction in tumor mass achieved by primary radiotherapy allowed radical resection of previously unresectable tumors [19].

In the treatment of carotid body tumors the surgical resection is the method of choice [2527]. In very large tumors their selective transarterial embolization may be applied preoperatively. This method has been for the first time successfully used by Schick and colleagues in 1980 [28]. It is aimed to block the vessels supplying the tumor without affecting the blood flow into the healthy tissue, the back-flow of the embolization agent into the carotid stream or its penetration into the distal circulation [29]. The benefit of preoperative embolization includes reduced perioperative blood loss and thus reduced need of transfusion [30, 31]. Moreover, tumor size uses to be reduced by $25 \%$ with this technique [32]. Reducing the blood supply to the tumor allows to determined the margins of resection more accurately and to reduce postoperative neurological disability [29]. The disadvantages include mainly the risk of postembolised stroke that occurs in more than 10\% of cases [32-34].

Because of the size of the tumor $(15 \times 8 \times 7 \mathrm{~cm})$ and its extent (according to Shamblin type III) our patient was treated by selective preoperative tumor embolization and its subsequent surgical removal.

\section{CONCLUSION}

In the case reported here we would like to point out the possible variability of clinical manifestations and morphological picture of Castleman's disease. The disease can affect any lymph-node in the body and simulate various nosological units. Location of the neck is described only in 14\% of cases. To our knowledge, there is no case of Castleman's disease imitating carotid body tumor published in the literature. Clinical examination and imaging methods in presented patient were helpful in predicting the disease, however, the histopathological analysis led to the final correct diagnosis. The treatment combined selective preoperative embolization and radical surgical resection and was chosen on the basis of the tumor size and its type.

\section{REFERENCES}

1. Castleman B, Iverson L, Menendez VP. Localized mediastinal lymph-node hyperplasia resembling thymoma. Cancer 1956; 9(4): 822-830.

2. Keller AR, Hochholzer L, Castleman B. Hyaline-vascular and plasma-cell types of giant lymph node hyperplasia of the mediastinum and other locations. Cancer 1972; 29(3): 670-83.

3. Liang J, Newman JG, Frank DM, Chalian AA. Cervical unicentric Castleman disease presenting as a neck mass: case report and review of the literature. Ear Nose Throat J 2009, 88(5): E8.

4. Gangopadhyay K, Mahasin ZZ, Kfoury H. Pathologic quiz case 2 - Castleman disease (giant lymph node hyperplasia). Arch Otolaryngol Head Neck Surg 1997; 123(10): 1137-1139.

5. Maruyama S, Hao N, Cheng J, Horino K, Ohnishi M, Fukushi M, Fujii M, Saku T. Castleman's disease of the buccal mucosa: Report of a case and review of the literature of head and neck cases. Oral Surg Oral Med Oral Pathol Oral Radiol Endod 2002; 93(3): 305-310. 
6. Shamblin WR, ReMine WH, Sheps SG, Harrison EG Jr. Carotid body tumor (chemodectoma). Clinicopathologic analysis of ninety cases. Am J Surg 1971; 122(6): 732-9.

7. Izumi M, Mochizuki M, Kuroda M, Iwaya K, Mukai K. Angiomyoid proliferative lesion: an unusual stroma-rich variant of Castleman's disease of hyaline-vascular type. Virchows Arch 2002; 441(4): 400-5.

8. Xu X, Wang Y, Ma H, Shao C, Jin G. Unicentric Castleman disease mimicking a pancreatic neoplasm. Am Surg 2012; 78(3): 178-80.

9. Good DJ, Gascoyne RD. Atypical lymphoid hyperplasia mimicking lymphoma. Hematol Oncol Clin North Am 2009; 23(4): 729-45.

10. Wang S-H, Ruan Z, Huang HL, Song KS. A rare case of Castleman disease presenting as pulmonary mass mimicking central pulmonary malignancy. Chin Med J (Engl) 2009; 122(8): 990-1.

11. Finn MA, Schmidt MH. Castleman disease of the spine mimicking a nerve sheath tumor. Case report. J Neurosurg Spine 2007; 6(5): 455-9.

12. Gupta NK, Torigian DA, Gefter WB, Marshall MB, Liang H, Carver JR, Miller WT Jr. Mediastinal Castleman disease mimicking mediastinal pulmonary sequestration. J Thorac Imaging 2005; 20(3): 229-32.

13. Cirillo RL Jr, Vitellas KM, Deyoung BR, Bennett WF. Castleman disease mimicking a hepatic neoplasm. Clin Imaging 1998; 22(2): 124-9.

14. Ylinen K, Sarlomo-Rikala M, Laatikainen T. Pelvic Castleman disease mimicking an adnexal tumor. Obstet Gynecol 1995; 85(5 Pt 2): 894-7.

15. Johnson WK, Ros PR, Powers C, Stoupis C, Segel KH. Castleman disease mimicking an aggressive retroperitoneal neoplasm. Abdom Imaging 1994; 19(4): 342-4.

16. Wang CP, Hsiao JK, Ko JY. Splaying of the carotid bifurcation caused by a cervical sympathetic chain schwannoma. Ann Otol Rhinol Laryngol 2004; 113(9): 696-9.

17. Casserly P, Kiely P, Fenton JE. Cervical sympathetic chain schwannoma masquerading as a carotid body tumour with a postoperative complication of first-bite syndrome. Eur Arch Otorhinolaryngol 2009; 266(10): 1659-62.

18. Benzoni E, Cojutti A, Intini S, Uzzau A, Bresadola F. Schwannoma of the sympathetic cervical chain presenting as a lateral cervical mass. Tumori 2003; 89(2): 211-2.

19. de Vries IA, van Acht MM, Demeyere TB, Lybeert ML, de Zoete JP, Nieuwenhuijzen GA. Neoadjuvant radiotherapy of primary irresectable unicentric Castleman's disease: a case report and review of the literature. Radiat Oncol 2010; 5: 7.

20. McCarty MJ, Vukelja SJ, Banks PM, Weiss RB. .Angiofollicular lymph node hyperplasia (Castleman's disease). Cancer Treat Rev 1995; 21(4): 291-310.

21. Shahidi H, Myers JL, Kvale PA. Castleman's disease. Mayo Clin Proc 1995; 70(10): 969-77.

22. Martino G, Cariati S, Tintisona O, Veneroso S, De Villa F, Vergine M, Monti M. Atypical lymphoproliferative disorders: Castleman's disease. Case report and review of the literature. Tumori 2004; 90(3): 352-5.

23. Chronowski GM, Ha CS, Wilder RB, Cabanillas F, Manning J, Cox JD. Treatment of unicentric and multicentric Castleman disease and the role of radiotherapy. Cancer 2001; 92(3): 670-6.

24. Dispenzieri A. Castleman disease. Cancer Treat Res 2008; 142: 293-330.

25. Westerband A, Hunter GC, Cintora I, Coulthard SW, Hinni ML, Gentile AT, Devine J, Mills JL. Current trends in the detection and management of carotid body tumors. J Vasc Surg 1998; 28(1): 84-92; discussion 92-3.

26. Linder F, Wagner M, Allenberg J, Koffler M. [Tumors of the glomus caroticum]. Chirurg 1984; 55(1): 19-24. German

27. Hallett JW Jr, Nora JD, Hollier LH, Cherry KJ Jr, Pairolero PC.Trends in neurovascular complications of surgical management for carotid body and cervical paragangliomas: a fifty-year experience with 153 tumors. J Vasc Surg 1988; 7(2): 284-91.

28. Schick PM, Hieshima GB, White RA, Fiaschetti FL, Mehringer CM, Grinnell VS, Everhart FR. Arterial catheter embolization followed by surgery for large chemodectoma. Surgery 1980; 87(4): 459-64.

29. Zeitler DM, Glick J, Har-El G. Preoperative embolization in carotid body tumor surgery: is it required? Ann Otol Rhinol Laryngol 2010; 119(5): 279-83.

30. Ward PH, Liu C, Vinuela F, Bentson JR. Embolization: an adjunctive measure for removal of carotid body tumors. Laryngoscope 1988; 98(12): 1287-91.

31. Muhm M, Polterauer P, Gstöttner W, Temmel A, Richling B, Undt G, Niederle B, Staudacher M, Ehringer H. Diagnostic and therapeutic approaches to carotid body tumors. Review of 24 patients. Arch Surg 1997; 132(3): 279-84.

32. Persky MS, Setton A, Niimi Y, Hartman J, Frank D, Berenstein A. Combined endovascular and surgical treatment of head and neck paragangliomas-a team approach. Head Neck 2002; 24(5): 423-31.

33. Robison JG, Shagets FW, Beckett WC Jr, Spies JB. A multidisciplinary approach to reducing morbidity and operative blood loss during resection of carotid body tumor. Surg Gynecol Obstet 1989; 168(2): 166-70.

34. Kafie FE, Freischlag JA. Carotid body tumors: the role of preoperative embolization. Ann Vasc Surg 2001; 15(2): 237-42.

Received: June, 15, 2012

Accepted: July 10, 2012 